DOI 10.37882/2223-2974.2021.03.26

\title{
ОСОБЕННОСТИ ОРГАНИЗАЦИИ МЕРОПРИЯТИЙ ФИЗКУЛЬТУРНО-ОЗДОРОВИТЕЛЬНОГО И СПОРТИВНОГО ХАРАКТЕРА: ПРАВОВЫЕ ОСНОВЫ
}

\section{FEATURES OF SPORTS AND \\ RECREATIONAL ACTIVITIES \\ ORGANIZATION: LEGAL PRINCIPLES \\ N. Plaksina \\ V. Shustov \\ E. Smirnova \\ T. Akulova \\ O. Nosik}

Summary: This article reveals the issues of safety and security arrangements of recreational and sports events. The authors indicate the relevance of the legal regulation of sports events on the basis of the presented statistical materials indicating an unfavorable terrorist situation in the countries of the world arena during sports events. A review of the main legal sources regulating mass events is carried out. The main stages and procedures of organizational activities during competitions and sports events in the UCTR named after D. Mendeleev.

Keywords: physical education, student sport, security and safety, mass sport events, public order, terrorism.
Плаксина Надежда Викторовна

старший преподаватель, ФГБОУ ВО «Российский химико-технологический университет

им. Д.И. Менделеева», г. Москва nadegda.compas@rambler.ru

Шустов Владислав Владимирович стариий преподаватель, ФГБОУВО

«Российский химико-хнологический университет им. Д.И. Менделеева», г. Москва shuvv@muctr.ru

Смирнова Елена Валерьевна к.т.н., старший преподаватель, ФГБОУ ВО «Российский химико-технологический университет им. Д.И. Менделеева», г. Москва evsmirnova@muctr.ru

Акулова Татьяна Николаевна Доцент, ФГБОУ ВО «Российский химико-технологический университет им. Д.И. Менделеева», г. Москва

takulova@muctr.ru

Носик Оксана Владимировна

Дочент, ФГБОУ ВО «Российский химико-технологический университет им. Д.И. Менделеева», г. Москва onosik@muctr.ru

Аннотация: В данной статье раскрываются вопросы обеспечения безопасности проведения физкультурно-оздоровительных и спортивных мероприятий. Авторами обозначена актуальность правового регулирования спортивных мероприятий на основе представленных статистических материалов, указывающих на неблагоприятную террористическую обстановку в странах мировой арены во время проведения спортивных состязаний. Проведен обзор основных правовых источников, регулирующих мероприятия массового характера. Обозначены основные этапы и процедуры организационной деятельности при проведении соревнований и спортивных мероприятий в РХТУ им. Д.И. Менделеева.

Ключевые слова: физическая культура, студенческий спорт, безопасность, массовые спортивные мероприятия, общественный порядок, терроризм.

(священное перемирие).

Мир меняется, подвергаются влиянию и традиции, когда-то ставшие нерушимыми и вечными, принципиальные основания которых, казалось бы, являлись безусловной и непререкаемой истиной.

Возрождённые Олимпийские игры в конце XIX века застали мир сильно изменившимся, в обиход человечества вошло понятие «террор». Основной и безумной целью этих носителей нечеловеческих принципов явля- 
ется необузданное желание путем совершения террористических актов устрашить общество и оказать давление на органы власти или международные организации для реализации своих политических и иных требований, и спортивные мероприятия практически идеально подошли для этих целей. Массовые скопления людей во время спортивных соревнований, вовлеченность широких масс болельщиков из разных стран, эмоциональный накал, освещение мероприятий в СМИ - всё это сделало спорт заманчивой мишенью для террористов.

Представляя статистику актов устрашения террористами, обращаем ваше внимание на следующие особенности: в качестве локальных зон для совершения преступлений террористы выбирают массовые инфраструктурные объекты; реализовывая свои преступные цели, выбирают в качестве субъектов деяний мирных и невинных людей, которыми движут события и впечатления и которые уж точно не находятся в ожидании последнего дня и часа своей жизни; акты носят циничный характер; любая цель, которая преследует смерть хотя бы одного человека, безумна и совершенно неоправданно и в ситуации спортивного состязания любого уровня, является, по крайней мере, подлой и жестокой (среди погибших в основном молодые).

А цифры и события, следующие:

1. Мюнхенская олимпиада 1972 года. Жертвами террористического акта стали спортсмены сборной команды Израиля - 11 человек

2. 1995 год во время встречи футбольных команд «Шахтер» и «Таврия» центральный стадион Донецка осветился мощным взрывом. В результате погибли шесть человек.

3. Олимпиада 1996 в Атланте. 27 июля 1996 года в Олимпийском парке, рядом с деревней, где жили и тренировались спортсмены, прогремел мощный взрыв. В результате теракта погибли 2 человека и 111 получили различные ранения

4. 9 мая 2004 года взрыв на центральной трибуне стадиона в Грозном. Погибли 7 человек, включая действующего главу Республики Ахмата Кадырова, более 50 ранено.

5. 14 мая 2010 года, Ирак (провинция Таль-Афар). Во время футбольного матча на стадионе взорвался автомобиль, начиненный взрывчаткой: 25 человек погибли, около сотни получили ранения.

6. В 2012 году в Эль-Хилла (Ирак). Завершающий этап матча юношеских сборных по футболу (финальный свисток) с синхронизацией введения в действие взрывного устройства закончился трагедией: погибших - 9, раненых- 32 (основная категория жертв - молодые спортсмены).

7. 27 февраля 2012 года, Могадишо, Сомали. В результате взрыва придорожной бомбы, произведенного рядом со стадионом во время фут- больного матча, трое зрителей погибли и семеро получили ранения.

8. 13 марта 2013 года взрыв на стадионе в Афганистане 5 погибших.

9. 15 апреля 2013 года на этапе финиширования марафона в Бостоне в продолжительном интервале в 12 секунд раздались два взрыва. Итог: погибли 3 человека, более 280 человек пострадали.

10. 4 января 2015 года, Пакистан: теракт на стадионе. Статистика жертв: 5 погибших (в том числе три игрока), 11 получили ранения.

Обозначая психологический портрет террориста, основываясь на основных психологических характеристиках и свойствах, которые в общей своей структуре и норме (общие закономерности развития) имеют устойчивые поведенческие векторы и обусловленности действий и деятельности как формы активности и целевой направленности и, подвергая анализу и обосновывая хоть какую-то логику в психике террориста, приходишь к выводу: личность преступника массовых убийств имеет не просто алогичную схему нормального восприятия действительности, а скорее подверглась полному искажению психических структур поведения и всех моральных и этических норм социума. Тем опаснее представляется человечеству эта категория «нелюдей»: отсутствует строгая логика; жестокость и безумие взглядов; приоритетные цели массовых гибелей людей; непредсказуемость действий и высокая степень угрозы для жизни простых и не вовлеченных в политические игры людей.

На современном этапе актуализируется необходимость противостоянию этой угрозе во всех сферах жизнедеятельности человека. Особую актуальность меры по предотвращению террористических угроз приобретают при организации массовых народных площадок, и в частности, в процессе проведения спортивных соревнований.

Обеспечение безопасности спортивных мероприятий стало насущной проблемой на международном и государственном уровне. Любопытным представляется следующий факт: в преддверии московской Олимпиады глава КГБ Юрий Андропов для борьбы с терроризмом создал легендарную группу «Альфа».

Естественным образом возникла необходимость подвергнуть вопросы безопасности проведения спортивных соревнований государственному регулированию. Обозначим основные положения Ф3- №3 «О физической культуре и спорте в Российской Федерации», в частности, в поле ведения и контроля режима проведения массовых мероприятий.

В соответствии с частью 1 статьи 20 Федерального закона «О физической культуре и спорте в Российской Фе- 
дерации»: «Организаторы физкультурных мероприятий или спортивных мероприятий несут ответственность за организацию и проведение таких мероприятий, а также при проведении официальных спортивных соревнований обеспечивают совместно с собственниками, пользователями объектов спорта меры общественного порядка и общественной безопасности». Нормативнозаконодательные позиции указанного правового акта регулируются Правилами обеспечения безопасности при проведении официальных спортивных соревнований (утв. постановлением Правительства РФ от 18 апреля 2014 г. N 353).

Приоритетным принципом упомянутого Федерального закона является принцип обеспечения безопасности жизни и здоровья лиц, занимающихся физической культурой и спортом, а также участников и зрителей, физкультурных и спортивных мероприятий (ст. 3).

Более того, функция по реализации обеспечительных мер общественного порядка и безопасности при проведении официальных физкультурных и спортивных мероприятий на объектах спорта - в полной мере возложена на Российскую Федерацию (п.19 ст. 6).

Обозначена в Ф3 «О физической культуре и спорте в Российской Федерации» и ответственность субъектов РФ на полномочном уровне, где в качестве функциональных обязанностей выделены следующие: содействие обеспечению общественного порядка и общественной безопасности при проведении официальных физкультурных и спортивных мероприятий на территориях субъектов Российской Федерации [1].

На уровне местного самоуправления и, в частности, территориальные муниципальные образования несут ответственность в обеспечении общественного порядка и общественной безопасности при проведении официальных физкультурных и спортивных мероприятий (п. 6 ч. 1 ст. 9; п. 3 ч. 1 ст. 8 ).

Уровень безопасности общественного порядка при проведении массовых и спортивных мероприятий регулируется и контролируется и другими правовыми источниками: от 7 февраля 2011 г. № 3-Ф3 «О полиции» и Приказ МВД России № 1092 (17.11.20150), где основные положения, касающиеся обеспечительных мер в поле массовости и спортивной деятельности сводятся к следующему:

1. На законодательном уровне РФ устанавливается обязанность органов полиции оказывать содействие организаторам спортивных, зрелищных и массовых мероприятий в обеспечении безопасности и общественного порядка в местах проведения этих мероприятий (ст. 12 глава 3) [2].

2. Утверждаются Требования к отдельным объектам инфраструктуры мест проведения официальных спортивных соревнований и техническому оснащению стадионов для обеспечения общественного порядка и общественной безопасности (Приказ МВД России № 1092 (17.11.20150) [3].

Вышеперечисленные законодательные акты, положения и требования правового порядка регулируют как «большие» спортивные соревнования, включённые в Единый календарный план межрегиональных, всероссийских и международных физкультурных мероприятий, и спортивных мероприятий (ЕКП), так и соревнования другого уровня, в частности студенческого спорта. Однако, если обеспечение безопасности соревнований ЕКП осуществляется по отлаженной схеме силами соответствующих государственных органов, то в случае, например, внутривузовских соревнований, вопросы безопасности ложатся на плечи организаторов (кафедра спорта). Сама организующая структура подобных мероприятий в Высшей школе касается не только вопросов контрольного и безопасного характера событийных массовых мероприятий в вузе, но и лежит в поле правовой ответственности. Вдвойне ответственно следует подходить к планированию спортивного мероприятия, обоснованному подходу к проведению спортивных состязаний и анализу всех составляющих элементов (алгоритмов) организации массового уровня с учетом всех возможных рисков и неблагоприятных последствий.

По анализу данных, на основании которых была обозначена и сформулирована проблемная область, целевым направлением стало выявление реальных недостатков при проведении массовых мероприятий, в частности соответствие уровня обеспечения правового порядка и соблюдение мер безопасности спортивномассовых мероприятий различной значимости, в высших образовательных учреждениях г. Москвы.

В спектре деятельности, направленной на достижение значимых результатов и цели поставленной авторами, в период с февраля 2019г., по декабрь 2020г., рабочей группой регулярно посещались различные спортивные мероприятия ведомственного, регионального и всероссийского значения. В перечень вошло 23 мероприятия, как внутренние, приводящиеся непосредственно вузами, на объектах принадлежащих непосредственно образовательным организациям, так и мероприятия с участием студенческой молодежи, организаторами которых выступали иные общественные структуры. Мероприятия были дифференцированы на 5 категорий, по количеству участников, включая спортсменов, зрителей, организаторов, судей, персонал. К первой категории отнесены мероприятия с численностью до 50 человек. K пятой категории были отнесены мероприятия с количеством участников от 500 до 1000 человек. Был определен реестр единых параметров (рисков), характеризующих 
относительную к уровню каждого мероприятия степень принятых мер безопасности проведения, а также критериев их соблюдения и оценки.

Выступая в качестве сторонних наблюдателей, члены рабочей группы определили следующие методы для получения достоверных целевых показателей: изучение анализ и структуризация информации, имеющейся в научно-методической литературе, наблюдение, шкалирование, проведение опросов и сбор необходимых данных по заданным параметрам, статистическая обработка результатов.

Для мероприятий массового характера, а именно: физкультурные и спортивные соревнования и встречи, не зависимо от их значимости, были определены следующие риски, которые ниже рассмотрим чуть подробнее:

- антитеррористическая защищённость;

- нарушение общественного порядка, криминал;

- риски пожарной безопасности;

- явления природного характера;

- риски медицинского характера.

Оценка каждого параметра, определённого в качестве индикаторного показателя соответствия и эффективности, принятых мер безопасности, проводилась путем выставления количества баллов по шкале от 1 до 5 баллов. Было принято условие выставления минимальной оценки не ниже 3 баллов. Установление данного минимума, объясняется применением даже на мероприятиях ведомственного уровня модели трех рубежного контроля: контроль прилегающей к спортивному объекту территории, пространства внутри самого объекта, контроля непосредственно осуществляющегося при входе в зону проведения соревнований (спортивный зал, манеж, бассейн, зрительские трибуны, открытие игровые площадки).

По итогам обработки полученных результатов, проведена сравнительная характеристика показателей и степени качества их обеспеченности непосредственно в период проведения спортивно массовых мероприятий, на основании которой авторами были выдвинуты следующие заключения и сформулирован ряд рекомендаций.

Количество участников мероприятий не определяет единой динамики для всех параметров (рисков), включенных в реестр оценки. Для некоторых большая массовость является мотивирующим условием для обеспечения наиболее высокой степени мер безопасности. К примеру, степень мер антитеррористической защищенности. Для других высокая плотность участников повышает долю вероятности проявления негативного фактора, риск нарушения общественного порядка, не смотря не принятые меры.
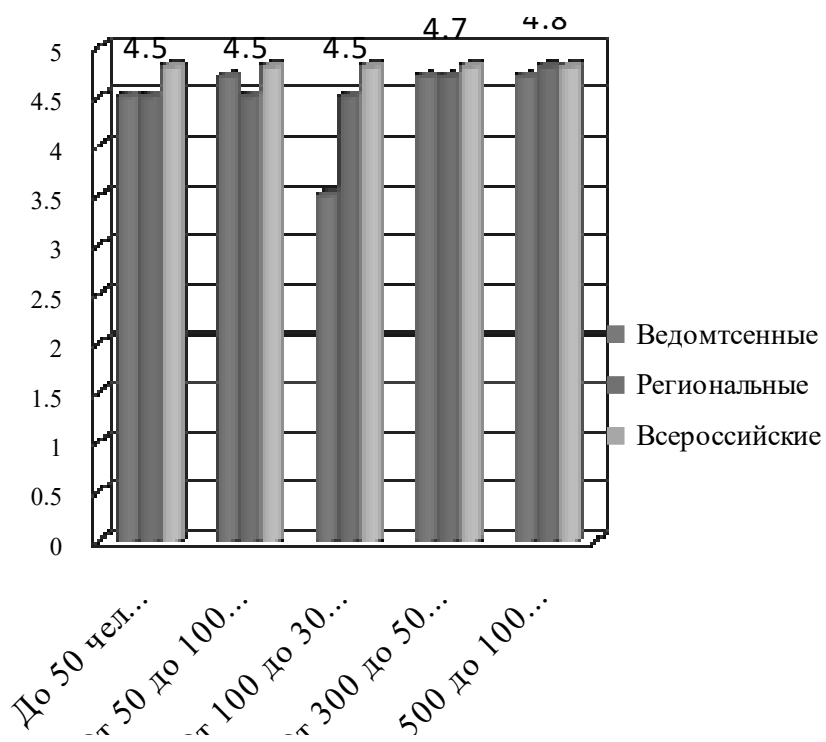

Рис. 1. Антитеррористическая защищенность
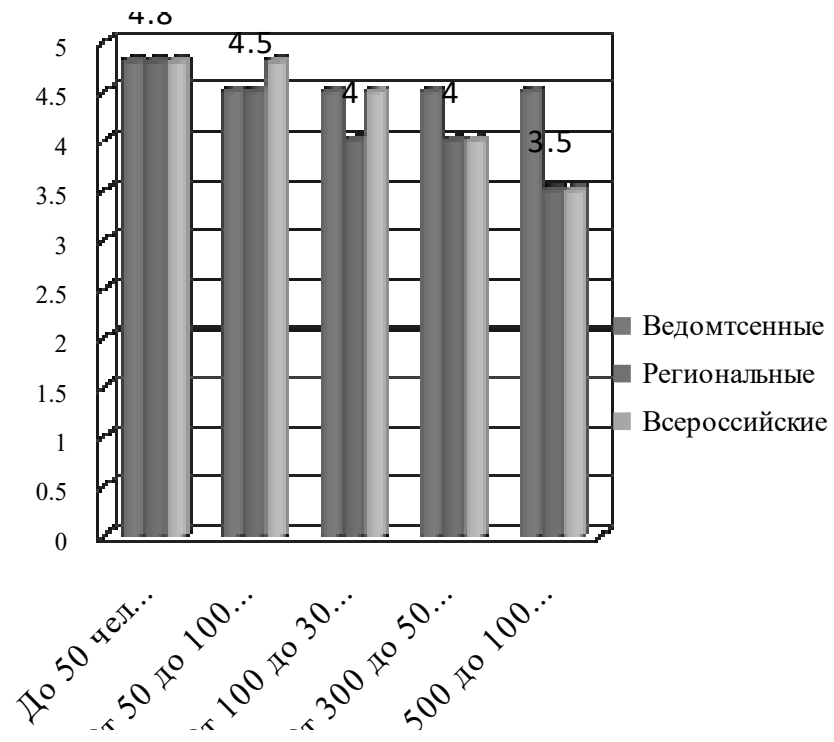

Рис. 2. Нарушение общественного порядка

По первым двум пунктам результаты оценки соответствия графически представлены на рисунках 1, 2. На основании данных можно рекомендовать организаторам мероприятий любого уровня, необходимо обязательное взаимодействие с профильными структурами вуза, либо службами органов безопасности муниципальных и региональных ведомств (СБ). При подготовке конкретного мероприятия необходимо довести до лица, отвечающего за обеспечение безопасности, точное время и продолжительность мероприятия, место его проведения, примерное количество и состав участников, а также программу и маршруты перемещения участников. В ходе мероприятия возможны антиобщественные проявления со стороны болельщиков, нарушение общественного порядка и правил внутреннего распорядка учреждения, порча имущества вуза, вандализм, а также хищение личного имущества участников мероприятия и 
другие противоправные действия. Необходимо заранее оговорить порядок контроля доступа участников на территорию объекта и в зону проведения непосредственно мероприятия, при необходимости предусмотреть краткий инструктаж представителей команд (тренеров) непосредственно перед началом мероприятия. Представители сторонних команд по договорённости заранее готовят список участников, болельщиков и других лиц на территорию объекта, обеспечивают наличие у них документов, удостоверяющих личность. В ходе инструктажа также оговаривается порядок хранения личных ценных вещей спортсменов во время мероприятия (электронные устройства, документы, деньги), которые они по понятным причинам не могут оставлять при себе.

В зоне ответственности пожарных служб: в случае если вопросы пожарной безопасности не входят в компетенцию СБ, отдельно привлекается структура или лицо, отвечающая за указанное направление. Представитель службы пожарной безопасности или ответственный, должен обладать той же информацией о мероприятии, что и сотрудник СБ. Оценив показатели по данному типу рисков (рисунок 3), можем заключить, что в обязательном порядке перед началом мероприятия он должен осмотреть место его проведения на предмет контроля состояния путей эвакуации, соответствия территорий и помещений заявленному числу участников, работоспособности систем противопожарной защиты, наличия и состояния первичных средств пожаротушения. При необходимости указанное лицо совместно с сотрудником СБ участвует в инструктаже представителей команд перед началом мероприятия, присутствует во время его проведения.
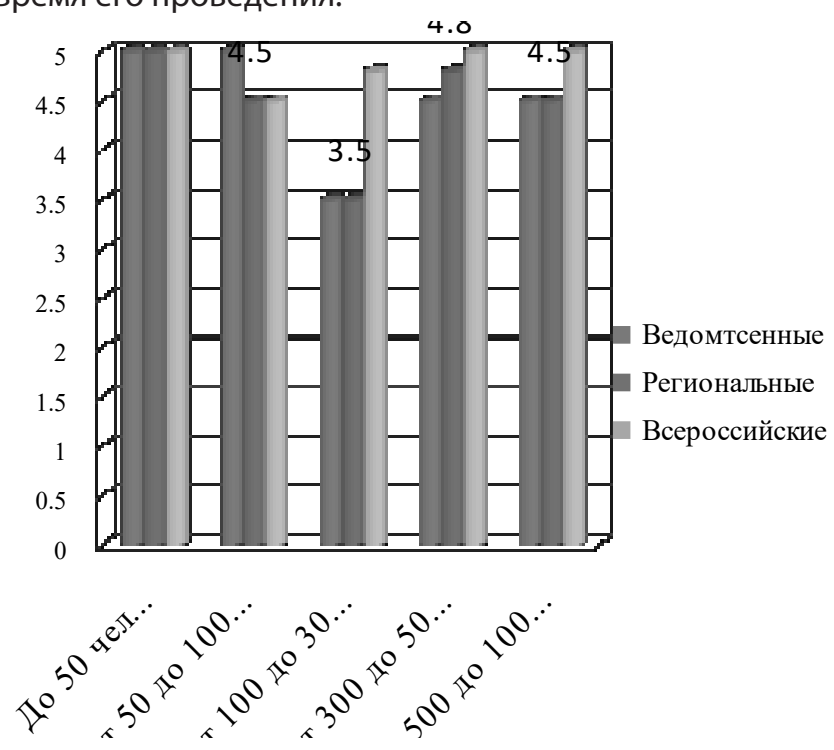

Рис. 3. Риски пожарной безопасности

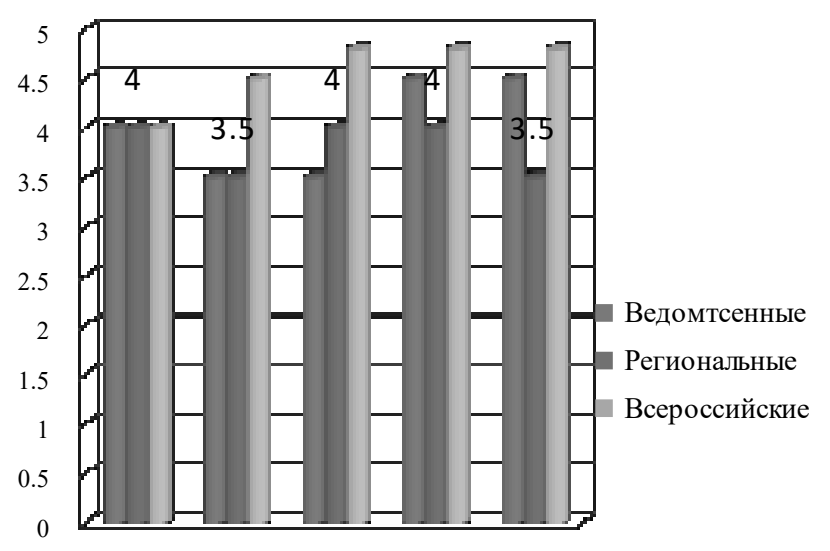

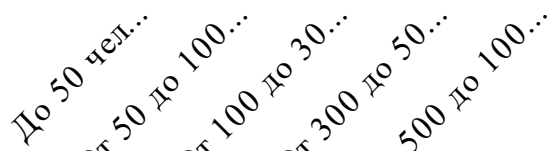

Рис. 4. Риски медицинского характера

Таким образом, организатор спортивного мероприятия делегирует часть ответственности по вопросам безопасности соответствующим структурам учреждения, организации (вуза), которые компетентны в них, и получает возможность сосредоточиться на других, более близких к спорту вопросах. В сущности, механизм взаимодействия организатора соревнований со структурами учреждения, отвечающими за обеспечения безопасности аналогичен таковому при проведении «больших» мероприятий с государственными органами, что не исключает возможности привлечения, например сотрудников органов внутренних дел при проведении соревнований любого уровня.

На основании упомянутой ранее Статьи 12 Федерального закона от 7 февраля 2011 г. № 3-Ф3 «О полиции» существует возможность обратиться в территориальный орган внутренних дел за помощью в обеспечении безопасности в случае масштабных мероприятий или проведения их за пределами учреждения (вуза). В случае присутствия на мероприятии указанных сотрудников структур учреждения или государственных органов, по аналогии или в соответствии с указанными ранее Требованиями, необходимо обеспечить стационарные условия места наблюдения: ограничить площадку визуализации от попадания осадков и прямого солнечного света (явления природного характера учитываются и в отношении участников соревнований).

Риски медицинского характера, оценка, которых представлена на рисунке 4, относятся к компетенции врачебного специалиста, который в обязательном порядке присутствует на всем протяжении соревновательных и спортивных мероприятий и готов оказать незамедлительную помощь в случае необходимости (если ситуация требует специфической помощи, необходимо 
принять меры по вызову неотложной помощи специалистов). В обязанности специалиста медицинского профиля входит также и функция наблюдения и контроля состояния соревнующихся (количественный состав медицинских специалистов устанавливается в зависимости от уровня соревнований и числа его участников).

Как показывает практика, при проведении спортивных мероприятий в вузе большую пользу может принести привлечение волонтёров из числа студентов в помощь организаторам. Студенты могут оказать существенную помощь при встрече и сопровождении участников мероприятия, оформлении документов, регистрации участников, проведении мероприятия, координации и информационной поддержкой гостей.

В РХТУ им. Д.И. Менделеева вошло в практику привлечение студентов специальной медицинской группы к организации и проведению соревнований. Таким образом, достигается сразу несколько целей. Студенты, в силу ограничений по здоровью и не имеющие возможности участвовать в спортивных состязаниях, вовлекаются в соревновательный процесс, приобщаются к физической культуре и спорту, при этом видят «кухню» мероприятия, вникают в тонкости организации и проведения спортивного мероприятия. При этом, занимаясь общественно полезной деятельностью, молодые люди «прокачивают softskills», «гибкие навыки», которые способствуют уверенности в себе и всё более ценятся в современном мире, в том числе и работодателями. При этом участие в спортивном мероприятии в качестве волонтёра может без натяжки быть зачтено как полноценное практическое занятие физической культурой. С некоторыми оговорками волонтёры могут быть задействованы, в том числе и в обеспечении безопасности. Численность и возможности служб безопасности по выделению сотрудников на обеспечение спортивного мероприятия могут быть ограничены, и «дополнительные глаза и уши» могут стать большим подспорьем в их деятельности. Важно, что волонтёры, особенно имеющие ограничения по состоянию здоровья, не должны сами вмешиваться при возникновении нештатных ситуаций, антиобщественного поведения, нарушения общественного порядка, правил внутреннего распорядка и т.д. Они не имеют статуса и полномочий на ряд действий, связанных с обеспечением безопасности, не обладают достаточными навыками. Но своевременно сообщить компетентным лицам или органам о возникновении угрозы безопасности вполне в их силах. В ряде случаев одним своим присутствием они могут предотвратить противоправные проявления (вандализм, хищение имущества и пр.). Всё это обязательно должно быть оговорено в ходе инструктажа перед началом мероприятия, обеспечена и проверена возможность волонтёра быстро связаться с лицом, отвечающим за обеспечение безопасности. В ходе мероприятия необходимо знать место нахождения привлекаемых лиц и периодически контролировать их.

Привлечение волонтеров к обеспечению и проведению массовых мероприятий имеет некоторые ограничения, которые носят как медицинский характер, так и психологические аспекты (нагрузки, тревожность, адаптивность, стрессоустойчивость, эмоционально-волевые характеристики).

По результатам обзора правовых источников, регулирующих деятельность массовых и физкультурных мероприятий, а также анализа качественной оценки организационных аспектов массовых студенческих турниров и состязаний спортивного уровня, авторы приходят к следующим выводам: любая деятельность с участием значительного количества ее участников требует особого контроля и регулирования, как на законодательном уровне, так и в поле ответственности администрации образовательного учреждения. Особый контроль проведения мероприятий категории «массовые» на текущий момент обосновывается высоким уровнем террористической опасности. Несмотря на периодические изменения, вносимые в документы различного уровня, регламентирующие обеспечение мер безопасности в данной сфере деятельности, проблема создания максимально благоприятных условий проведения остается актуальной.

\section{ЛИТЕРАТУРА}

1. Федеральный закон от 4 декабря 2007 г. № 329-Ф3 (в ред. от 31.07.2020) «0 физической культуре и спорте в Российской Федерации» // Собрание законодательства РФ. 2007. № 50. Ст. 6242; 2020. № 31. Ст. 5033.

2. Постановление Правительства РФ от 18 апреля 2014 № 353 «0б утверждении Правил обеспечения безопасности при проведении официальных спортивных соревнований» // Собрание законодательства РФ от 5 мая 2014 г. № 18 (часть IV). Ст. 2194.

3. Федеральный закон от 7 февраля 2011 г. № 3-Ф3 (в ред. от 06.02.2020) «0 полиции» // Собрание законодательства РФ. 2011. № 7. Ст. 900; 2020. № 6. Ст. 591.

4. Приказ МВД России от 17 ноября 2015 № 1092 «0б утверждении Требований к отдельным объектам инфраструктуры мест проведения официальных спортивных соревнований и техническому оснащению стадионов для обеспечения общественного порядка и общественной безопасности»; зарегистрирован в Минюсте России 31 декабря 2015 года, регистрационный № 40464 // Текст приказа опубликован на «Официальном интернет-портале правовой информации» (www.pravo.gov.ru) 12 января 2016 г. 
5. Агаев Р.А., Шанько В.В., Стецун М.Ю. Организация и правовые основы охраны общественного порядка и общественной безопасности спортивных мероприятий // Юристъ Правоведъ. 2019. - № 1 (88). С. 36 - 4

6. Мурзин Д.В., Ольховский Р.М. Вопросы правового регулирования общественно полезных услуг в области физической культуры и массового спорта // Российский юридический журнал. 2017. № 6. С. 172 - 183.

7. Песков А.Н. Терроризм и проблемы обеспечения безопасности Олимпийских игр // Право и государство: теория и практика. 2013 - №7

( П Плаксина Надежда Викторовна (nadegda.compas@rambler.ru), Шустов Владислав Владимирович (shuvv@muctr.ru), Смирнова Елена Валерьевна (evsmirnova@muctr.ru), Акулова Татьяна Николаевна (takulova@muctr.ru), Носик Оксана Владимировна (onosik@muctr.ru).

Журнал «Современная наука: актуальные проблемы теории и практики»

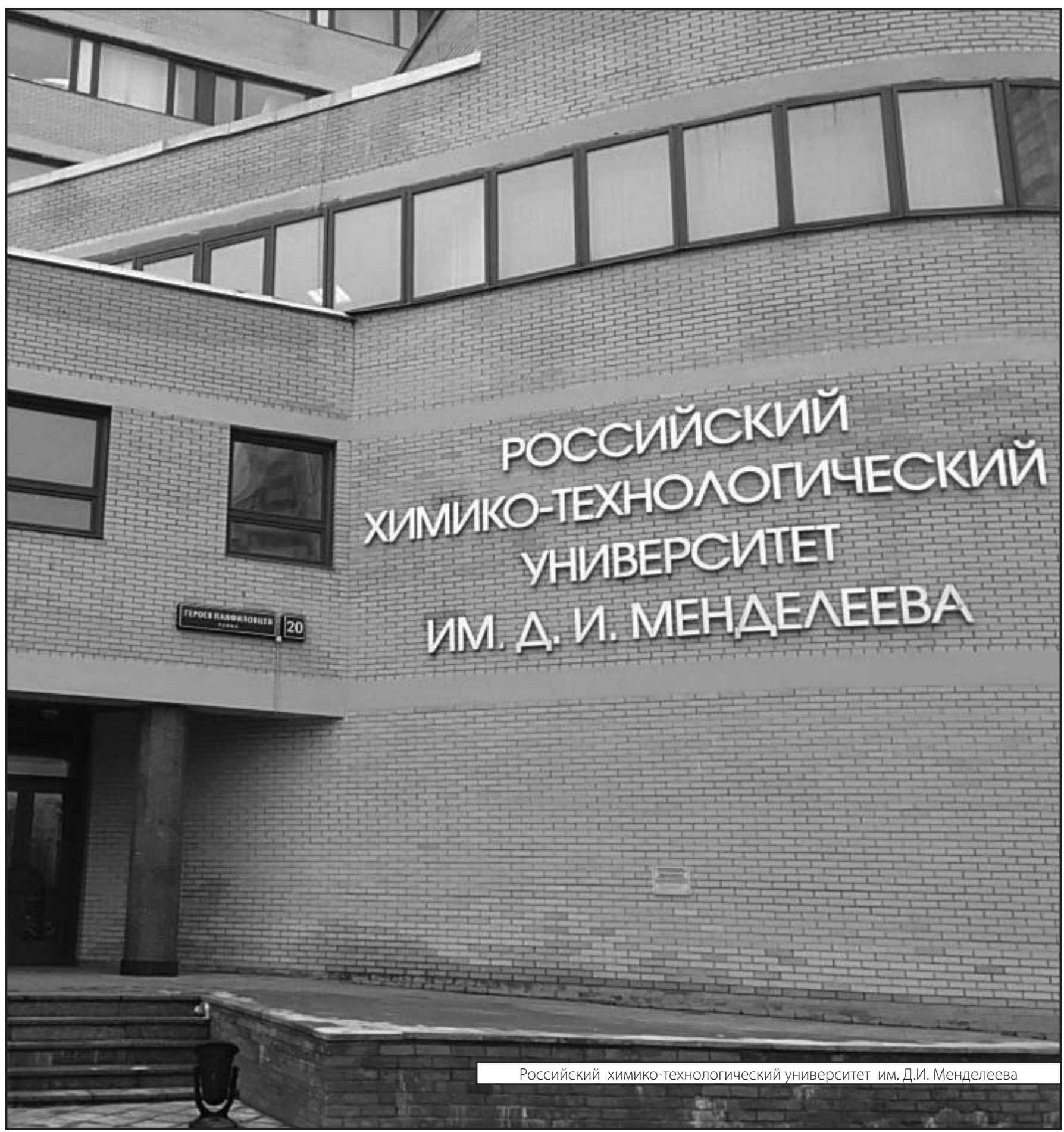

